\title{
Desain dan Implementasi Mesin Pengolah Limbah Ikan
}

\author{
Neilcy Tjahya Mooniarsih ${ }^{1)}$, Sumiyattinah ${ }^{2)}$ \\ ${ }^{1)}$ Staf Pengajar Program Studi Teknik Elektro, \\ ${ }^{2)}$ Staf Pengajar Program Studi Teknik Sipil, Fakultas Teknik \\ Universitas Tanjungpura Pontianak \\ e-mail : neilcyte@gmail.com ${ }^{1)}$, yattinah@yahoo.co.id ${ }^{2)}$
}

\begin{abstract}
Sungai Pinyuh merupakan salah satu kecamatan di kabupaten Pontianak, yang berada di pesisir pantai laut Natuna dan sebagian besar penduduknya berprofesi sebagai nelayan. Namun potensi sumber daya perikanan dan kelautan hingga saat ini masih sangat terbatas dan belum mereka manfaatkan secara maksimal. Besarnya potensi perikanan di Kabupaten Pontianak khususnya di kecamatan Sungai Pinyuh berbanding terbalik dengan kesejahteraan masyarakat nelayan di sana. Penduduk di kecamatan Sungai Pinyuh masih banyak yang berada dibawah garis kemiskinan, dan sebagian besar diantaranya adalah penduduk pra sejahtera. Kehidupan nelayan sangat bergantung kepada musim. Pada musim kemarau mereka mendapatkan ikan untuk dijual atau diolah menjadi ikan asin atau berbagai jenis pengolahan ikan lainnya. Ketika musim penghujan, angin kencang, dan gelombang tinggi, nelayan tidak bisa melaut dan ini berarti bahwa mereka tidak memiliki pendapatan. Sementara limbah ikan yang dihasilkan dari hasil tangkapan mereka terbuang dengan percuma karena keterbatasan modal dan teknologi. Permasalahan yang muncul pada kelompok budidaya ikan air tawar di kabupaten Pontianak adalah mahalnya harga pakan ikan. Padahal limbah ikan dapat dimanfaatkan sebagai bahan baku dari pelet ikan, yang sangat dibutuhkan oleh kelompok usaha budidaya ikan air tawar di kabupaten Pontianak. Mesin pencetak pelet ikan dengan memanfaatkan limbah ikan yang terbuang menjadi pakan ikan merupakan salah satu solusi untuk mengatasi permasalahan mahalnya harga pakan ikan dan melimpahnya limbah ikan yang belum termanfaatkan, sehingga dapat meningkatkan kesejahteraan kelompok usaha ikan di kabupaten Pontianak.
\end{abstract}

Keywords- Nelayan, limbah ikan, mesin pelet ikan.

\section{Pendahuluan}

Kabupaten Pontianak yang terdiri dari 9 kecamatan, 60 desa serta 7 kelurahan mempunyai luas 1.276,9 $\mathrm{Km}^{2}$. Jumlah penduduk Kabupaten Pontianak berdasarkan data dari Dinas Dukcapil Kabupaten Pontianak, sampai dengan bulan April 2010 berjumlah 254.409 jiwa, terdiri dari laki-laki sebanyak 129.849 jiwa dan perempuan sebanyak 124.560 jiwa. Kecamatan Sungai Pinyuh adalah salah satu kecamatan di Kabupaten
Pontianak, dikarenakan desa-desa di wilayah kecamatan ini berada di pesisir atau tepi pantai Laut Natuna maka sebagian besar penduduknya bekerja sebagai nelayan. Selain itu produksi ikan budidaya air tawar di kabupaten Pontianak juga sangat besar, seperti: ikan mas 559,5 ton per tahun, ikan nila 280,8 ton per tahun, ikan lele 139,7 ton per tahun, sebagaimana diperlihatkan pada Tabel 1 dan Tabel 2.

TABEL 1

Jumlah Produksi Perikanan Budidaya, TANGKap Dan Pengolahan Kabupaten Pontianak Periode Januari - Juni TAHUN 2011

\begin{tabular}{lcccccc}
\hline \multirow{2}{*}{ Jenis } & \multicolumn{7}{c}{ Jumlah Produksi Perbulan (Ton) } \\
\cline { 2 - 7 } & $\mathbf{1}$ & $\mathbf{2}$ & $\mathbf{3}$ & $\mathbf{4}$ & $\mathbf{5}$ & $\mathbf{6}$ \\
\hline $\begin{array}{l}\text { Perikanan } \\
\text { Budidaya }\end{array}$ & 60,30 & 58,00 & 50,08 & 52,60 & 51,75 & 66,75 \\
\hline $\begin{array}{l}\text { Perikanan } \\
\text { Tangkap }\end{array}$ & 413,6 & 489,7 & 555,6 & 734,9 & 478,5 & 740,2 \\
\hline $\begin{array}{l}\text { Produk } \\
\text { Olahan }\end{array}$ & 25,06 & 41,50 & 36,14 & 60,70 & 61,21 & 61,39 \\
\hline
\end{tabular}

Sumber: Dinas Perikanan dan Kelautan Kabupaten Pontianak

TABEL 2

Jumlah PRODUKSI PERIKANAN BudidAya, TANGKAP DAN PEngolahan KabuPATEN PontianaK PERIOdE JUliDESEMBER TAHUN 2011

\begin{tabular}{lcccccc}
\hline \multirow{2}{*}{ Jenis } & \multicolumn{7}{c}{ Jumlah Produksi Perbulan (Ton) } \\
\cline { 2 - 7 } & $\mathbf{7}$ & $\mathbf{8}$ & $\mathbf{9}$ & $\mathbf{1 0}$ & $\mathbf{1 1}$ & $\mathbf{1 2}$ \\
\hline $\begin{array}{l}\text { Perikanan } \\
\text { Budidaya }\end{array}$ & 69,71 & 62,14 & 43,40 & 62,90 & 64,30 & 50,00 \\
\hline $\begin{array}{l}\text { Perikanan } \\
\text { Tangkap }\end{array}$ & 789,7 & 715,7 & 508,7 & 475,8 & 468,9 & 409,3 \\
\hline $\begin{array}{l}\text { Produk } \\
\text { Olahan }\end{array}$ & 62,71 & 43,72 & 34,87 & 35,12 & 27,71 & 7,87 \\
\hline
\end{tabular}

Sumber: Dinas Perikanan dan Kelautan Kabupaten Pontianak

Jumlah kelompok karamba/budidaya ikan air tawar sebanyak 78 kelompok. Masing-masing kelompok beranggotakan 10 orang. Setiap anggota kelompok mempunyai 4 sampai dengan 6 karamba. Budidaya ikan air tawar dimulai dari membesarkan bibit sampai dengan siap untuk dipanen. Bibit ikan diperoleh dari Balai Benih Ikan di Anjungan. Membutuhkan waktu 4-5 bulan untuk siap dipanen. Setelah ikan besar akan dibeli oleh agen untuk didistribusikan ke Sanggau, Kuala dan Balai Karangan. Harga partai besar untuk nila per-kilonya Rp 22.500 sedangkan mas Rp 26.000 untuk Pengecer sekilo nila dihargai $\mathrm{Rp} 32.000$ dan $\mathrm{Rp} 27.000$ untuk nila. Kelompok Borneo Arwana memiliki 38 karamba. Untuk 5000 bibit ikan diperlukan 4 karamba dibutuhkan 40-50 
karung pelet selama proses pembesaran ikan. Harga perkarung dengan berat $30 \mathrm{~kg}$ adalah $\mathrm{Rp} 285.000$. Keuntungan kotor yang diperoleh selama 4-5 bulan masa pembesaran berkisar Rp. 3.840.000. Akan tetapi keuntungan bisa berkurang dengan susahnya didapat pelet ikan, sehingga harga pelet melambung tinggi. Dalam memanfaatkan sumber daya perikanan Kabupaten Pontianak terdapat 3 Unit Pelelangan Ikan dan 14 unit pengolahan ikan yang tersebar di 6 kecamatan serta 100 kelompok usaha penangkapan dan penampung usaha perikanan. Tenaga kerja yang terserap dari sektor perikanan mencapai 6.400 orang. Dampak dari aktifitas nelayan banyak tumbuh pengusaha perikanan baik itu agen-agen penampung maupun industri pengolahan ikan. Namun pemanfaatan potensi sumberdaya perikanan dan kelautan hingga saat ini masih sangat terbatas dan belum dimanfaatkan secara optimal. Industri pengolahan ikan masih didominasi oleh pengolahan ebi, kerupuk ikan, ikan asin, ikan asin tipis, pengasapan/pemanggangan. Dilihat dari besarnya potensi perikanan di Kabupaten Pontianak khususnya di kecamatan Sungai Pinyuh sangat berbanding terbalik dengan kesejahteraan masyarakat nelayan di sana. Kehidupan nelayan sangat bergantung kepada musim, apabila musim kemarau mereka mendapatkan ikan untuk dijual atau diolah menjadi ikan asin atau berbagai jenis pengolahan ikan lainnya. Ketika musim penghujan, angin kencang, dan gelombang tinggi, para nelayan otomatis tidak bisa melaut dan ini berarti tidak ada pendapatan. Penduduk di kecamatan Sungai Pinyuh masih banyak yang berada dibawah garis kemiskinan, dan sebagian besar diantaranya adalah penduduk pra sejahtera. Sementara limbah ikan yang dihasilkan dari hasil tangkapan karena keterbatasan teknologi masih terbuang dengan percuma. Padahal limbah ikan merupakan bahan baku dari Pelet Ikan, yang sangat dibutuhkan oleh kelompok usaha budidaya ikan air tawar di kabupaten Pontianak.

\section{Permasalahan Mitra dan Solusi}

Hasil survey dilapangan mengkemukakan bahwa permasalahan yang dihadapi oleh kelompok nelayan pengolah ikan dan kelompok usaha budidaya air tawar di kabupaten Pontianak adalah:

- Mahalnya harga pakan ikan/pelet sehingga memberatkan bagi kelompok usaha bididaya ikan air tawar di wilayah kabupaten Pontianak. Di Kabupaten Pontianak terdapat beberapa tempat pelelangan dan pendaratan ikan. Limbah ikan yang dihasilkan di kecamatan Sungai Pinyuh dapat mencapai 10 ton per hari. Harga limbah ikan di Kecamatan Sungai Pinyuh Rp 400/kg s/d Rp 500/kg, apabila dikembangkan melalui usaha pembuatan pelet ikan akan dapat meningkatkan penghasilan kelompok nelayan pengolah ikan laut tersebut. Keterbatasan pemahaman pengembangan usaha sektor perikanan laut pasca panen yaitu pengolahan hasil tangkapan ikan laut masih terbatas kepada pengeringan ikan, ikan asin tipis, pembuatan kerupuk ikan, udang ebi. Sedangkan limbah ikan hasil tangkapan seperti ikan-ikan dengan ukuran kecil ataupun jenis ikan yang kurang disukai oleh nelayan tidak dimanfaatkan atau dibuang.

- Nelayan melakukan kegiatan pengeringan ikan berdasarkan pesanan, apabila tidak ada pemesan maka kelompok nelayan ini tidak mempunyai pekerjaan.

- Pengolahan ikan seperti ikan asin tipis, kerupuk ikan tidak dapat diandalkan sebagai penambah penghasilan, karena sulitnya pemasaran.

- Terbatasnya akses bantuan modal usaha untuk pengembangan pengolahan hasil perikanan bagi nelayan kecil dan menengah.

- Keterbatasan sarana dan prasarana pendukung yang menunjang terhadap penghasilan kelompok nelayan pengolah ikan laut tersebut.

Hal-hal tersebut di atas menjadi dasar pertimbangan tim pelaksana untuk melakukan kegiatan Pengabdian Kepada Masyarakat di kelurahan Sungai Pinyuh kecamatan Sungai Pinyuh dan kelurahan Terusan di kecamatan Mempawah Hilir Kabupaten Pontianak, dengan mengadakan sosialisasi dan percontohan dalam pembuatan mesin pelet ikan, yang juga merupakan kegiatan lanjutan dari rancang bangun sebelumnya, yang dilaksanakan pada tahun 2013, yaitu membuat alat pengolah limbah ikan menjadi tepung ikan. Dari tepung ikan untuk menjadi pelet ikan masih diperlukan teknologi untuk mencetak pelet, yang disebut Mesin Pelet Ikan. Sehingga masyarakat yang selama ini menjual limbah ikan dengan harga murah dan membuangnya karena tidak dapat mengolahnya maka kegiatan ini akan menjadi peluang usaha untuk meningkatkan kesejahteraan nelayan. Karena usaha ini mempunyai prospek pemasarann yang sangat bagus, pengolahan limbah ikan menjadi pelet ikan dengan teknologi tepat guna dapat dimanfaatkan untuk pakan ikan dan ternak. Kegiatan ini diadakan juga dalam rangka menerapkan hasil penelitian yang telah dilakukan dan diharapkan dalam langkah selanjutnya dapat meningkatkan taraf hidup masyarakat nelayan dan kelompok usaha budidaya air tawar di Kabupaten Pontianak melalui penciptaan peluang usaha pengolahan ikan laut pasca panen. Solusi dan peluang yang ditawarkan adalah sebagai berikut:

- Ketersediaan bahan baku pembuatan pelet ikan, hal ini mengingat sangat melimpahnya limbah ikan di Desa Sungai Kunyit, yang kebanyakan terbuang tidak diamanfaatkan serta dengan harga $\mathrm{Rp} 500, / \mathrm{kg}$.

- Keadaan kelompok nelayan ditinjau dari segi aktifitas maupun tenaga kerja sangat memungkinkan untuk memproduksi pelet ikan.

- Adanya peluang pemasaran pelet ikan yang sangat potensial baik dikecamatan Sungai Pinyuh maupun kecamatan Mempawah Hilir Kabupaten Pontianak. Untuk pemasaran lokal ditujukan kepada pemilik budidaya ikan air taawar, pemilik karamba, peternak ayam potong, ayam petelur, ikan serta secara nasional adanya ketergantungan pemerintah kepada impor pelet ikan. 
Berdasarkan produksi dan nilai produksi perikanan budidaya dapat dilihat potensi perikanan budidaya di Kabupaten Pontianak. Dengan melihat potensi tersebut maka usaha pembuatan pelet ikan akan sangat menguntungkan bagi nelayan. Lebih dari itu, komoditas pelet ikan memiliki peluang pemasaran yang prospektif baik untuk pasaran dalam maupun luar negeri.

\section{Desain Mesin Pembuat Pelet Ikan}

Bahan dasar pelet ikan adalah tepung ikan (marine fish meal) yang merupakan salah satu produk pengawetan ikan dalam bentuk kering, kemudian digiling menjadi tepung. Bahan baku tepung ikan umumnya adalah ikan-ikan yang kurang ekonomis, Pelet ikan terdiri dari komposisi 30\% tepung ikan, 30\% dedak, 20\% bungkil kelapa, dan 20\% bahan-bahan lainnya. Feasibility study industri pelet ikan dapat dilaksanakan jika secara ekonomi menguntungkan. Oleh karena itu perlu dilakukan suatu kajian baik mengenai pasar, proses produksi termasuk ketersediaan bahan bakunya, serta analisis keuangan dan ekonomi serta analisis dampak lingkungan. Dengan berkembangnya budidaya karamba, budidaya ikan lele, industri tambak udang dan usaha pakan ternak di Indonesia, permintaan terhadap pelet ikan akan terus meningkat. Oleh sebab itu, investasi bidang usaha industri pelet ikan sangat prospektif untuk dikembangkan.

\section{A. Spesifikasi Mesin Pencetak Pelet Ikan}

Mesin pencetak pelet ikan sebagaimana diperlihatkan pada Gambar 1 dirancang dengan spesifikasi sebagai berikut:

- Dimensi seluruh mesin: $1400 \mathrm{~mm}$ x 678mm x1188 mm

- Dimensi bagian pembentuk pelet: Ø $300 \mathrm{~mm}$ x $800 \mathrm{~mm}$

- Engine: Diesel 6,5 HP

- Penerus Daya: Pulley + V-Belt

- Bagian utama Mesin: Screew, screen, dan rotating knife.

Bahan-bahan yang diperlukan untuk membuat sebuah mesin pelet ikan diperlihatkan pada Tabel 3.

TABEL 3

Bahan Pembuat Mesin Pelet Ikan

\begin{tabular}{|c|c|c|}
\hline No & Nama Bahan & Kuantitas \\
\hline 1 & Mesin Diesel 6,5 HP & 1 Unit \\
\hline 2 & Steel Plate $2 \mathrm{~mm}$ & 1 Keping \\
\hline 3 & Steel Plate $5 \mathrm{~mm}$ & 1 Keping \\
\hline 4 & Besi Siku 5 x $5 \mathrm{~cm}$ & 3 Batang \\
\hline 5 & Pipa Galvanis $\propto 12$ Inch & 1 Batang \\
\hline 6 & Flange 14 Inch & 2 Buah \\
\hline 7 & Besi UNP 4 Inch & $1 \mathrm{Buah}$ \\
\hline 8 & Bearing UCP 205 & 2 Buah \\
\hline 9 & Steel Plate $10 \mathrm{~mm}$ & 1 Keping \\
\hline 10 & Poros Rod Bar Q $80 \mathrm{~mm}$ & 1 Batang \\
\hline 11 & Mur + Baut M 13 & 25 Buah \\
\hline 12 & Mur + Baut M 15 & $10 \mathrm{Buah}$ \\
\hline 13 & Roda pulley $Q 10$ inch & 1 Buah \\
\hline 14 & Roda pulley $Q 4$ inch & 1 Buah \\
\hline 15 & Poros Rod Bar $\propto 50 \mathrm{~mm}$ & 1 Batang \\
\hline 16 & V-belt & 1 Buah \\
\hline
\end{tabular}

Usaha pengolahan tepung ikan dan pembuatan pelet ikan dapat dikembangkan dengan biaya yang tidak terlalu besar. Bahan-bahan untuk membuat tepung ikan dapat diperoleh dari perairan dangkal pesisir kabupaten
Pontianak seperti ikan Petek (Leiognathus equulus), ikan Kuniran (Upeneus tragula) dan sisa filleting Demang atau ikan Merah (Lutjanus inalabaricus), ikan sembilang. Kajian finansial dilakukan dengan menyajikan nilai investasi dan analisis biaya pembuatan pelet ikan per $\mathrm{kg}$, sehingga dapat ditetapkan harga pokok. Dan keadaan kelompok nelayan, baik ditinjau dari segi aktivitas kelompok maupun tenaga kerja keluarga, sangatlah dimungkinkan bagi kelompok atau keluarga nelayan untuk memproduksikan pelet ikan. Dengan demikian bahan-bahan yang sebelumnya tidak terpakai seperti ikan-ikan kecil dan ikan yang kurang layak dikonsumsi dapat dijadikan sebuah peluang usaha yang menjanjikan.

\section{B. Rancang Bangun Kontruksi Mesin}

Rangka utama menggunakan besi UNP, penyambungan menggunakan las listrik. Bagian utama mesin, screew dibuat menggunakan besi rood bar di tengahnya serta plat besi yang dibentuk lingkaran memanjang sesuai gambar, penyambungan dengan menggunakan las listrik.

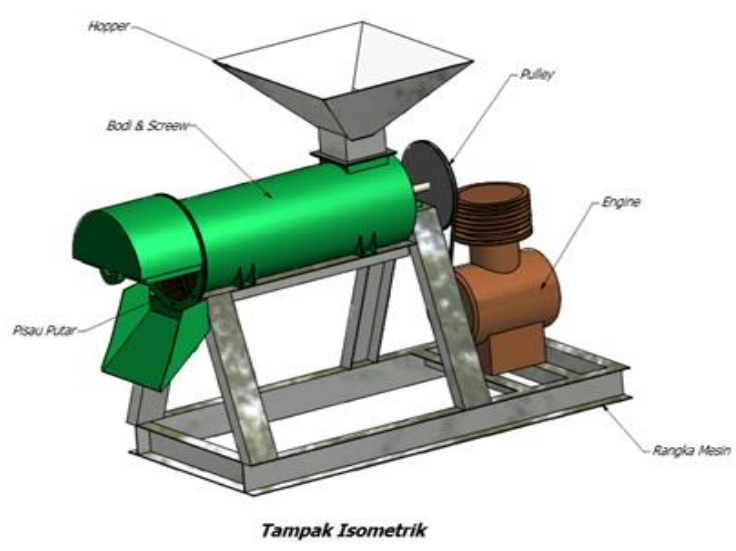

Gambar 1 Rancang bangun mesin pembuat pelet ikan

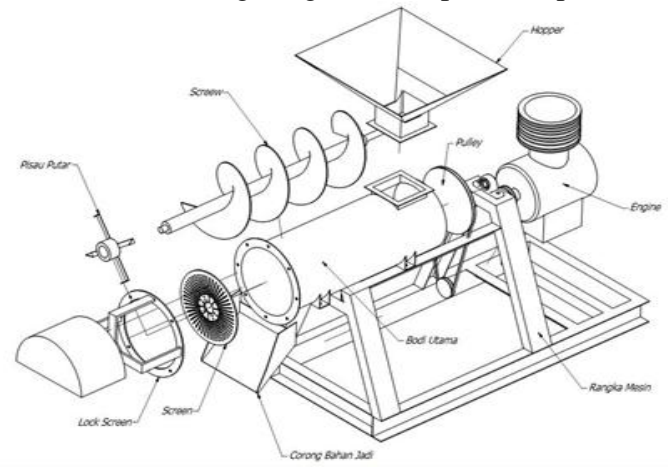

Gambar 2 Detail sistem mesin pembuat pelet ikan

Bodi utama menggunakan pipa galvanis dengan ukuran yang di sesuaikan, hooper dan corong menggunakan plar besi yang di bentuk sesuai kebutuhan dengan cara pengelasan. Untuk screen dibuat dengan plat besi tebal dan di beri lubang kecil untuk membentuk adonan menjadi bentuk yang diinginkan, dengan proses pengerjaannya dengan di mesin bor dengan mata bor sesuai kebutuhan yang di inginkan. Untuk rotating knife (pisau putar) mempunyai 4 sisi pisau yang dilekatkan di 
poros screew, namun diletakan setelah screen, pisau ini dipasang dengan menggun akan pasak dan baut agar dapat mudah dilepas pada saat penggantian mata pisaunya. Pisau ini berfungsi untuk memotong adonan agar tidak memanjang, dan diperoleh produk dengan ukuran sesuai yang diinginkan.

\section{Cara Kerja Mesin Pembuat Pelet Ikan}

Mesin pelet ini menggunakan system screew yang akan berputar guna menekan adonan pellet untuk keluar menuju screen yang mempunyai lubang berdiameter sesuai kebutuhan. Setelah engine atau sumber pengerak menyala, screew yang terdapat di dalam tabung akan berputar. Adonan pelet (campuran tepung ikan, bungkil kelapa, dedak dan pasir) yang sudah siap untuk dicetak/dibentuk dimasukan ke dalam hooper mesin pellet tersebut. Adonan tersebut akan diputar oleh screew dan di bawa kedepan untuk di tekan dan melewati screen, adonan tersebut akan melewati celah lubang-lubang screen sehingga adonan berbentuk panjang. Namun adonan tersebut akan di potong oleh rotating knife (pisau putar) yang berfungsi memotong adonan yang melewati screen tersebut sehingga adonan tidak jadi memanjang namun akan di potong menjadi kecil-kecil berbentuk tabung kecil-kecil. Potongan adonan tersebut akan jatuh dengan sendirinya ke corong penampung dan dapat di tampung oleh tempat yang di sediakan. Setelah itu adonan yang sudah di bentuk tersebut dijemur/dikeringkan.

\section{Implementasi Hasil Rancangan}

Hasil implementasi rancang bangun sistem mesin pencetak pelet ikan diperlihatkan pada Gambar (3)-(6).

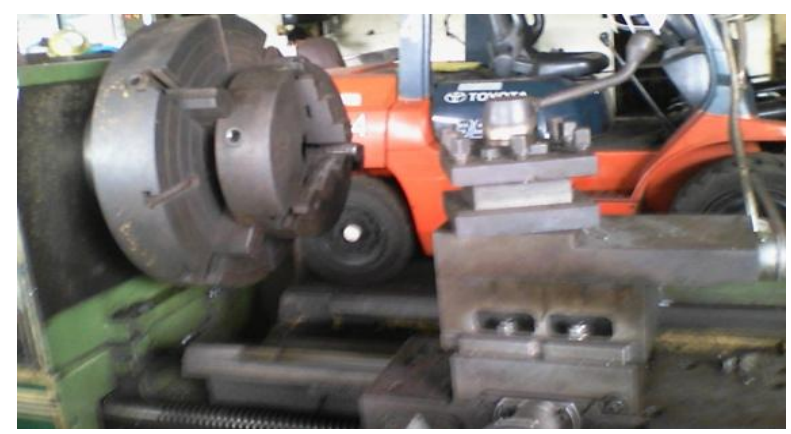

Gambar 3 Proses pembubutan dalam pembuatan shaft untuk screw

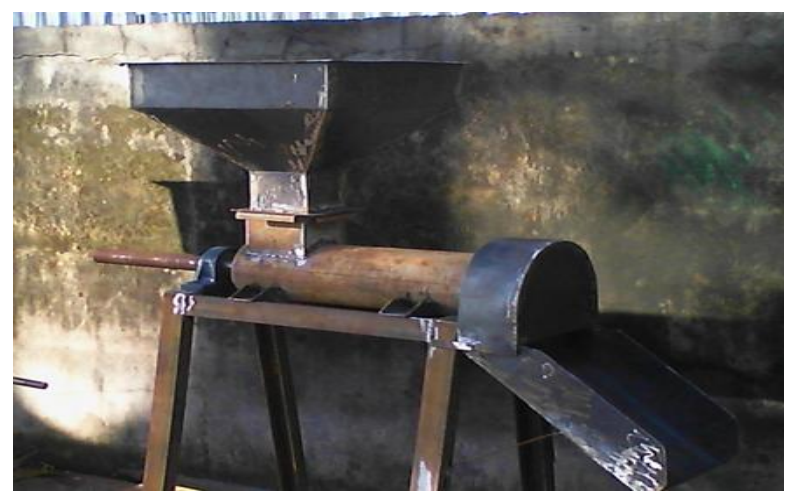

Gambar 4 Mesin Pencetak pellet setelah di rakit

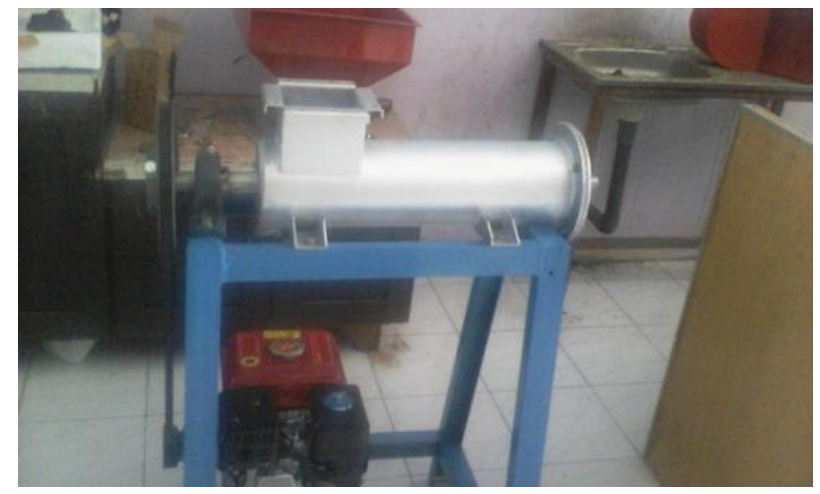

Gambar 5 Posisi pemasangan engine

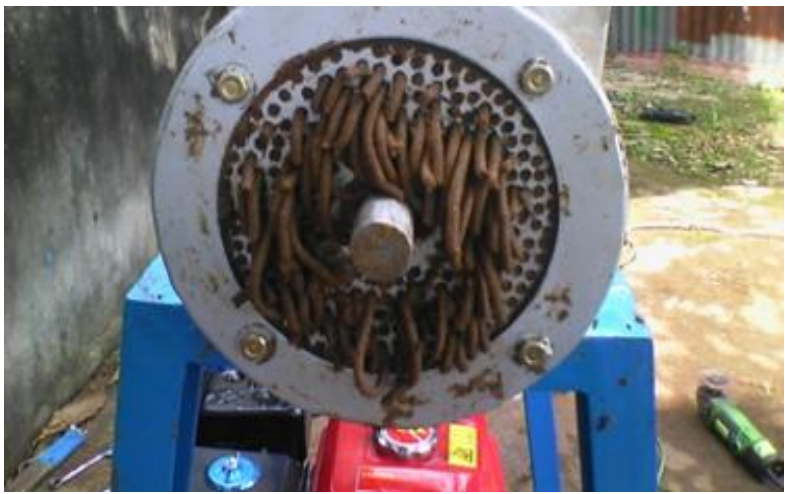

Gambar 6 Hasil keluaran pelet yang melalui screen

\section{KESIMPULAN}

Kabupaten Pontianak memiliki cukup bahan baku ikan yang dapat memenuhi industri pelet ikan, jika ditinjau dari kapasitas produksi lestari dan kapasitas produksi hasil penangkapan. Dalam rangka memecahkan masalah pengembangan usaha pengolahan ikan laut pasca panen dengan mengolah limbah ikan menjadi pelet ikan, maka sebagai pilot proyek dilaksanakan pada KUBE Nelayan DK Karya di kelurahan Sungai Pinyuh kecamatan Sungai Pinyuh Kabupaten Pontianak dengan pertimbangan bahwa desa ini merupakan ibukota kecamatan, dengan tingkat aktifitas kegiatan nelayan yang lebih besar dari desadesa lainnya. Sedangkan untuk pemasaran sebagai Mitra Konsumen adalah KUBE Borneo Arwana di kelurahan Terusan di kecamatan Mempawah Hilir kabupaten Pontianak dengan bidang usaha budidaya ikan air tawar seperti nila dan ikan mas. Sebagai produsen tepung ikan dan pelet ikan adalah KUBE (Kelompok Usaha Bersama) DK Karya kelurahan Sungai Pinyuh Kecamatan Sungai Pinyuh Kabupaten Pontianak. Pemasaran Pelet Ikan hasil produksi KUBE Nelayan DK Karya dapat dipasarkan kepada konsumen yaitu peternak unggas, pemilik karamba, maupun kelompok budidaya ikan air tawar. Menurut keterangan ketua KUBE Borneo Arwana, dengan membuat pelet dengan menggunakan tepung ikan yang diproduksi sendiri akan dapat menghemat biaya pakan ikan sebesar $30 \%$. Pelet ikan dibuat dengan komposisi $30 \%$ tepung ikan, $30 \%$ 
dedak, 20\% bungkil kelapa dan $20 \%$ bahan-bahan lainnya. Berarti dalam satu karung diperlukan $8,3 \mathrm{~kg}$ tepung ikan. Apabila tepung ikan diproduksi dengan harga $\mathrm{Rp} \mathrm{500/kg} \mathrm{dengan} \mathrm{harga} \mathrm{tepung} \mathrm{ikan} \mathrm{dipasaran} \mathrm{Rp}$ $12.500 / \mathrm{kg}$ maka akan menghemat biaya pembuatan pelet $\mathrm{Rp} 12.000 / \mathrm{kg}$. Sedangkan tepung ikan yang dapat dipasarkan oleh KUBE DK Karya untuk keperluan KUBE Borneo Arwana sebanyak $30 \%$ x $1500 \mathrm{~kg}=450$ kg. Strategi pemasaran diberikan kepada kelompok nelayan dengan memberikan data dan informasi tentang peluang pemasaran produksi pelet ikan. Tahap merintis usaha yaitu pemasaran dilakukan oleh kelompok nelayan dengan mendatangi pemilik usaha budiay air tawar dan pemilik karamba di sekitar di wilayah Kabupaten Pontianak bertujuan untuk memperkenalkan produk guna mengefektifkan promosi langsung kepada konsumen. Serta menjamin mutu pelet ikan dan menjaga ketersediaan produk pelet ikan. Sebagai mitra dalam Pelaksanaan Program Ipteks bagi Masyarakat, KUBE nelayan DK Karya di kelurahan Sungai Pinyuh kecamatan Sungai Pinyuh Kabupaten Pontianak, KUBE nelayan ini diharapkan dapat menjadi Pilot Project usaha pembuatan pelet ikan bagi kelompok nelayan lainnya dan sebagai pembanding untuk survey pemasaran adalah KUBE Borneo Arwana yang bergerak di bidang usaha budidaya ikan air tawar. Secara rinci hasil yang telah dicapai dari penelitian ini adalah:

- Menyelesaikan pembuatan instalasi unit Teknologi Tepat Guna (TTG) Mesin Pembuat Pelet Ikan sesuai spesifikasi usulan pada proposal. Mesin Pembuat Pelet Ikan yang sudah jadi di serahkan kepada kelompok nelayan di kecamatan sungai pinyuh.

- Melakukan pengujian unit instalasi TTG Mesin Pembuat Pelet Ikan dan berhasil dengan baik, sesuai dengan tujuan yang diinginkan. Dengan adanya Mesin Pembuat Pelet Ikan maka akan memudahkan masyrakat dalam mengolah limbah ikan untuk di buat pelet sehingga dapat mengurangi biaya pakan dalam pemeliharaan ikan.

- Melakukan sosialisasi langsung kepada masyarakat, tokoh masyarakat dan instansi yang terkait. Cara penggunaan TTG Mesin Pembuat Pelet Ikan, beserta cara pemeliharaan dan perawatannya. Dengan adanya sosialisasi ini diharapkan masyakat paham tentang tata cara penggunaan dan pemeliharaan alat tersebut sehingga penggunaan alat tersebut dapat berlangsung dalam jangka panjang.

- Memetakan potensi konsumen pelet ikan sebagai strategi pemasaran dan kelangsungan usaha selanjutnya.

\section{Referensi}

[1] Anonim, "Tepung Telur, Ikan Asin, Aneka Pindang, Bandeng Presto (Duri Lunak), Chicken Nugget, Tekno Pangan \& Agroindustri”, vol. 1 no. 8.

[2] Dinas Perikanan Kabupaten Pontianak, "Data Keragaan Pola Pemanfaatan Hasil Perikanan Kabupaten Pontianak", 2012.

[3] Dinas Sosial Tenaga Kerja Dan Transmigrasi Kabupaten Pontianak, "Data KUBE Fakir Miskin Kabupaten Pontianak", 2012.

[4] Kecamatan Sungai Kunyit, "Profil Kecamatan Sungai Kunyit, 2011.

[5] Rosdaneli, "Proses Pengeringan, Fakultas Teknik Prodi Teknik Kimia, Medan”, 2005. 